\title{
CONTRIBUIÇÕES DO PROGRAMA RESIDÊNCIA PEDAGÓGICA NA FORMAÇÃO DO ALFABETIZADOR DA EJA
}

\section{CONTRIBUTIONS OF THE PEDAGOGICAL RESIDENCE PROGRAM IN THE TRAINING OF EJA LITERACY}

\author{
Elizabete Ramalho Procópio ${ }^{1 *}$, Georgina Maria Faria Mucci ${ }^{2}$, Juliana de Paula Iennaco ${ }^{3}$ \\ ${ }^{1}$ Mestre em Educação pela UFJF, Faculdades Integradas de Cataguases, Cataguases, Universidade do Estado de Minas Gerais \\ UEMG, MG, Brasil, elizabete@unis.edu.br \\ ${ }^{2}$ Doutora em Ciências Biológicas pela UNESP, Faculdades Integradas de Cataguases, Cataguases, Faculdades Sudamérica, \\ Cataguases, MG, Brasil, georgina.mucci@professor.unis.edu.br \\ ${ }^{3}$ Mestre em Letras pela PUC-Minas, Faculdades Integradas de Cataguases, Cataguases, MG, Brasil, juliana.iennaco@unis.edu.br \\ * Autor para correspondência.
}

\section{Resumo}

Este artigo buscou analisar e discutir as práticas pedagógicas desenvolvidas na Educação de Jovens e Adultos (EJA), pelos acadêmicos (residentes) do curso de Pedagogia das Faculdades Integradas de Cataguases, participantes do Programa Residência Pedagógica (CAPES), bem como verificar as contribuições do programa para a formação docente. O programa foi realizado em uma escola pública em Cataguases - MG, e oportunizou aos acadêmicos de Pedagogia a experimentarem in loco as vivências e a dinâmica de uma sala de aula, supervisionados por professores da IES e da escola envolvida, além de possibilitar um exitoso estágio curricular. Essa imersão na educação básica permitiu ao residente uma relação reflexiva na construção de seu fazer docente. Os dados foram obtidos por meio da análise dos relatórios dos residentes, e de artigos sobre a temática de formação de professores, embasados nas discussões de autores referência na área. As bases da teoria de Paulo Freire direcionaram a práxis dos residentes/ acadêmicos. Para os discentes da escola campo, a presença dos residentes na sala de aula permitiu aos mesmos um atendimento mais específico. Pode-se dizer que no bojo do desenvolvimento do Programa Residência Pedagógica com alunos da EJA, os residentes obtiveram uma maior propriedade sobre as características dessa modalidade de ensino, e uma melhor percepção dos desafios para atuar na alfabetização de jovens e adultos na atualidade.

Palavras-chave: Residência Pedagógica. Formação docente. EJA. Alfabetização.

\begin{abstract}
This article sought to analyze and discuss the pedagogical practices developed in Youth and Adult Education (EJA) by academics (residents) of the Pedagogy course at Faculdades Integradas de Cataguases, participants in the Pedagogical Residency Program (CAPES), as well as to verify the contributions of the program for teacher training. The program was carried out in a public school in Cataguases - MG. It provided the opportunity for Pedagogy students to experience the experiences and dynamics of a classroom on the spot, under the supervision of teachers from IES and the school involved, and to enable a successful curricular internship. This immersion in basic education allowed the resident to have a reflexive relationship in constructing his teaching practice. Data were obtained through the analysis of the residents' reports and articles on the theme of teacher training, based on the discussions of reference authors in the area. The foundations of Paulo Freire's theory directed the practice of residents/academics. For students from a rural school, residents' presence in the classroom allowed them to provide more specific assistance. It can be said that during the development of the Pedagogical Residency Program with students from EJA, residents obtained greater ownership over the characteristics of this teaching modality and a better perception of the challenges to act in the literacy of young people and adults today.
\end{abstract}

Keywords: Pedagogical Residence. Teacher training. Youth and adult education. Literacy.

(C)UNIS-MG. All rights reserved. 


\section{INTRODUÇÃO}

Atualmente, pode-se dizer que a oferta de ensino em todos os níveis e segmentos acontece na rede pública no Brasil, por orientação da LDB 9694/96, mas ainda com formatos de organização que muitas vezes não favorecem o aprendizado e as características da EJA, principalmente no que se refere à construção da identidade desse alunado (FERREIRA e VITORINO 2019). Frequentemente as salas são muito heterogêneas nas etapas de alfabetização, com estudantes no início do processo e outros mais avançados, na leitura e na escrita. Geralmente, tem-se apenas um professor para atuar nessa sala multisseriada de jovens, adultos e idosos. Observa-se presente nesse contexto, as dicotomias "corpo/mente", vigentes nas escolas, em que o jovem ou adulto é visto apenas como "mente incorpórea" (ARROYO, 2017).

O público da EJA, por diferentes dificuldades e dinâmicas sociais foi excluído da educação regular, e através de alguns programas e políticas públicas no Brasil ao longo dos tempos, buscamse incluí-los. No entanto, essa inclusão não acontece de forma homogênea; muitos alunos acabam se perdendo na trajetória escolar, impactados pela desigualdade social e/ou fragilidades estruturais, didáticas e metodológicas desses projetos, que acabam os afastando desse processo de inclusão. Paulo Freire $(1996,2005,2011)$ em seus estudos, demonstrou a educação como possibilidade transformadora, mas que ainda não tem o status que merece para proporcionar a mudança do que está estabelecido em nossa sociedade.

A perspectiva dialógica e crítica Freireana são permeadas pela proposta de uma atuação comprometida, com a mudança social e com a consciência da não neutralidade do trabalho pedagógico nesse segmento. O referido autor propõe uma educação que possibilite ao oprimido, a se reconhecer como tal, numa tomada de consciência crítica, assumindo posições ativas pela conquista da sua liberdade e afirmação no mundo, juntamente com aqueles que com eles em verdade se solidarizam. Da mesma forma, a abordagem construtivista, esclarece o processo por que passa o alfabetizando (criança, jovem ou adulto) até se tornar um usuário competente da leitura e da escrita. Assim, é preciso considerar que o conhecimento não é dado como pronto e acabado, e sim num processo contínuo de desenvolvimento das potências/capacidades intelectuais e cognitivas do aluno, num sistema dialógico entre ensino e aprendizagem (BECKER 1993; FERREIRO e TEBEROSKY 1984).

A relevância desse trabalho se deve ao fato de uma grande parcela de adultos brasileiros, cerca de seis milhões, segundo o IBGE (2018) não serem alfabetizados. De acordo com Paiva (2006) a EJA assume a perspectiva de inclusão em sociedades democráticas. Isso traz à tona discussões sobre questões seculares de exclusão e de não comprometimento efetivo com a parcela de menos favorecidos, que continuam sem o direito à permanência na escola no Brasil. Nesse contexto, de acordo com Paiva et al. (2019) a EJA se consolidou no horizonte de direitos por meio de pressão de grupos, indivíduos e movimentos e se fortaleceu também aliada a outras demandas que nasceram a partir da luta por inclusão social.

O presente trabalho tem por objetivos analisar e discutir as práticas pedagógicas desenvolvidas na Educação de Jovens e Adultos (EJA), em uma escola pública, pelos estudantes/residentes de Pedagogia das Faculdades Integradas de Cataguases, participantes do Programa Residência Pedagógica (CAPES), bem como verificar as contribuições desse Programa para a formação docente dos residentes. 


\section{FUNDAMENTAÇÃO TEÓRICA}

Para entender a trajetória da Educação de Jovens e Adultos no Brasil, faz-se necessário percorrer historicamente os principais fatos que marcaram a constituição deste segmento e, discutir o Programa Residência Pedagógica como uma oportunidade para o Residente vivenciar, refletir e construir a sua prática pedagógica. Destacou-se assim, a importância do Programa Residência Pedagógica na formação de futuros professores para atuar nesse contexto diverso e negligenciado.

Dessa forma, buscar-se-á discutir esse importante percurso com vistas a alinhar a fundamentação teórica das ideias que constituem a base da formação de professores perpassando pela EJA, tendo como pano de fundo, o Programa Residência Pedagógica. As discussões propostas neste artigo, se embasam nas reflexões propostas por Freire $(2005,1996)$; Grossi $(2010)$; Ferreiro $(1983,1984)$ Vygotsky (1998), bem como nas discussões de Arroyo (2017), dentre outros.

\subsection{A EJA no Brasil: Trajetórias de lutas, desafios e conquistas para a formação do alfabetizador}

A Educação de Jovens e Adultos no Brasil, segundo Paiva (1973) se iniciou com a chegada dos Jesuítas em terras brasileiras, que ensinavam através da catequização indígena por meio da transmissão da língua portuguesa, com a finalidade de doutrinação religiosa. Com a vinda da família real em 1808, apresenta-se a necessidade de se instrumentalizar os indivíduos para as novas demandas técnicas e burocráticas que se colocam na sociedade, para atender a corte portuguesa e a aristocracia que se forma.

No final do século XIX, ocorreu o surgimento de novas escolas para adultos devido à melhoria das condições econômicas do país. Na década de 30, já no século XX, a EJA se consolida, sendo prevista na Constituição de 1934, através do Plano Nacional de Educação que designa que é dever do Estado o ensino primário, de frequência obrigatória com direito extensivo aos adultos.

Segundo Paiva (1973), a década de 40 é considerada uma década importante para a EJA tanto na esfera política, quanto pedagógica. Nesse período se deu a criação do INEP, foi realizado o I Congresso Educacional de Educação de Adultos, ocorreu o surgimento das primeiras obras dedicadas ao ensino supletivo e também implementada uma Campanha de Educação de Adolescentes e Adultos. Entretanto, de acordo com que é relatado na Proposta Curricular para EJA (2001), o adulto era considerado menos capaz do que a criança para aprender, sendo visto como marginal destituído do direito e também do potencial de aprendizagem. Com o tempo, essa visão foi questionada pelos próprios educadores brasileiros, como, por exemplo, em artigo de Lourenço Filho, em 1945, que lança mão de estudos em psicologia experimental realizados nos Estados Unidos na década de 20 e 30, que desconstrói a visão anterior.

O II Congresso Nacional de Educação de Adultos, ocorrido em 1958, também foi um marco para a EJA no Brasil, sendo uma iniciativa da sociedade civil, incomodada pela situação do analfabetismo e paralela à ação governamental. Nessa época, as ideias de Paulo Freire apontavam que a condição do analfabeto está intimamente ligada a uma situação social de desigualdade, e não igualitária, convocando a responsabilidade social e política de todos os envolvidos no processo educacional.

Com relação à formação do profissional para exercício nessa modalidade de ensino nessa época, se destacam as discussões de Soares (2008):

Com base na ação do voluntariado, a primeira Campanha Nacional de Educação de Adultos no Brasil, lançada em 1947, passou a ser sistematicamente criticada por não preparar adequadamente professores para trabalhar com essa população. No I Congresso Nacional

Interação, Varginha, MG, v. 23, n. 1, p. 25-37, 2021, ISSN 1517-848X / ISSN 2446-9874. 
de Educação de Adultos, realizado no Rio de Janeiro, ainda em 1947, já eram ressaltadas as especificidades das ações educativas em diferentes níveis e se recomendava uma preparação adequada para se trabalhar com adultos. Passados mais de dez anos, no II Congresso Nacional de Educação de Adultos, realizado em 1958, as críticas à ausência de formação específica para o professorado, assim como à falta de métodos e conteúdos pensados particularmente para a educação de adultos, tornaram-se ainda mais agudas, explícitas e generalizadas. (SOARES, 2008 p.89).

A partir da década de 60, o pensamento de Paulo Freire inspirou as ações da época, bem como sua proposta pedagógica alcançou vários programas de alfabetização e educação popular, que se realizaram em todo país. Esses programas foram empreendidos por estudantes, intelectuais e católicos engajados com as questões populares. Em 1964 foi aprovado o Plano Nacional de Alfabetização, que disseminaria a proposta de Paulo Freire por todo o país. No mesmo ano, porém, com o golpe militar, foi interrompido todo esse planejamento. De 1964 a 1985, pode-se dizer que a EJA esteve ligada a iniciativas como o MOBRAL (Movimento Brasileiro de Alfabetização) como uma resposta do governo militar às ideias de Paulo Freire.

Entretanto, desde a década de 1980, buscam-se compreender as rupturas, avanços e possibilidades bem como as permanências, recuos e limites na constituição desse campo de atuação e de pesquisa. Algumas questões ainda se mantêm até os dias atuais, como o fato de não se reconhecer o direito dos jovens e dos adultos populares à educação. (SOARES E PEDROSO 2016).

Com a abertura política e a constituição de 1988, são retomadas as discussões para esse segmento da educação. Percebe-se a necessidade de ampliação do entendimento das etapas necessárias ao processo de alfabetização, para que o mesmo não se realizasse em poucos meses como no passado, requerendo uma continuidade no processo e preparação de material didático específico.

Nessa época (década de 80) também os educadores começam a basear suas práticas nas pesquisas de Emília Ferreiro, que enfatiza a necessidade de não haver montagem de uma estrutura textual artificial para ler e escrever, mas sim de maneiras de ampliar o universo linguístico do aluno a ser alfabetizado. (FERREIRO E TEBEROSKY, 1984).

Na década de 90 as ações para EJA, como consta na Proposta Curricular para esse segmento, não foram muito profícuas de políticas para o setor, chegando a esse período com ações de oferta, apenas por alguns municípios e setores da sociedade civil. Entretanto, com a promulgação da LDB 9394/96, reconhece-se as características da Educação de Jovens e Adultos, e em seu inciso VII do Art. 4으, a Lei estabelece a necessidade de atenção às especificidades desse segmento e ao estudante do ensino noturno, como também enfatiza o Parecer CEB/CNE 11/ 2000.

Soares (2008) nos aponta que somado a esse contexto de uma fragilidade nas ações que constituem a EJA, os desafios relacionados à formação de professores também complexificam o ensino na atualidade:

Ainda que não seja uma questão propriamente nova, somente nas últimas décadas o problema da formação de educadores para a EJA, ganhou dimensão mais ampla. Esse novo patamar em que a discussão se coloca, relaciona-se à própria configuração do campo da Educação de Jovens e Adultos. Nesse sentido, a formação dos educadores tem se inserido na problemática mais ampla da instituição da EJA como um campo pedagógico específico que, desse modo, requer a profissionalização de seus agentes. (SOARES, 2008, p. 85).

Para Machado (2000) a formação para se trabalhar com esse segmento ainda é ineficiente e aligeirada, geralmente realizada por meio de cursos e treinamentos. Nesse contexto, destaca-se a 
necessidade de formação inicial específica consistente, nos cursos de graduação e pós-graduação como a formação continuada, por exemplo, em cursos de extensão.

Diante do exposto a formação de professores para esse segmento, há que considerar um refinamento de suas práticas, elencando diferentes procedimentos e conhecendo bem os jovens e adultos populares. Para Arroyo (2006, p. 22), é importante saber o perfil desses alfabetizandos da EJA, pois "são jovens e adultos com rosto, com histórias, com cor, com trajetórias sócio-étnicoraciais, do campo, da periferia". Os processos formativos desses educadores necessitam partir da prática pedagógica, permeada pela teorização sobre ela num processo de reflexibilidade.

\subsection{O Programa Residência Pedagógica}

O Programa Residência Pedagógica ${ }^{1}$ é uma das ações que integram a Política Nacional de Formação de Professores no Brasil, e tem por objetivo favorecer a imersão dos residentes/licenciandos nas escolas de Educação Básica, a partir da segunda metade do curso de licenciatura. Esse contato do residente/graduando com a escola campo (onde é desenvolvido o projeto) é estabelecido através do planejamento de atividades a serem realizadas. Entre essas ações estão: a análise de documentos (projeto político pedagógico, regimento e etc), participação em reuniões de Conselho de Classe, observação e regência de aulas, Intervenções Pedagógicas, entre outras. Essas práticas são sempre acompanhadas por um professor da unidade escolar, denominado preceptor, com experiência na área de ensino do residente/licenciando, sob a orientação de um docente (Professor orientador) da sua Instituição Formadora.

Pode-se considerar que esse formato de Programa, que articula a teoria à prática, se constitui e abarca uma rede de formadores, que se conjugam em torno do desenvolvimento do futuro docente da educação básica, na rede pública de ensino.

Para melhor entendimento do funcionamento do Programa e discussões posteriores no âmbito do presente trabalho, far-se-á uma breve descrição de como o mesmo acontece. A IES é selecionada por meio de edital público nacional pelo qual são apresentados os Projetos Institucionais que contemplam uma série de quesitos que direcionam o trabalho de todos os envolvidos no processo. No desenvolvimento do projeto, são realizadas várias etapas: Ambientação, Imersão, Regência de Classe e Avaliação. A realização do Projeto se dá via acordo de Cooperação Técnica firmado entre o Governo Federal e Secretarias Municipais e Estaduais de Educação. A IES envolvida tem apoio com a concessão de bolsas nas seguintes modalidades: Residente (discente matriculado a partir do quinto período do curso de licenciatura), Coordenador Institucional, Docente Orientador (docentes da IES selecionada) e Preceptor (professor da escola da educação básica).

O Programa Residência Pedagógica, instituído pelo governo federal em 2018, permite que se tenham subprojetos que contemplem diferentes licenciaturas. De acordo com o edital que rege o programa, as atividades realizadas pelo residente na escola campo, devem fazer parte do Projeto de Estágio Docência da IES selecionada, devendo o mesmo ser incorporado ao Projeto Pedagógico do curso. O planejamento deve prever todas as etapas elencadas no edital.

A imersão do residente/licenciando na prática pedagógica no momento de seu percurso formativo na graduação favorece a construção do profissional reflexivo, que com base em suas

\footnotetext{
1 http://portal.mec.gov.br/component/tags/tag/45681
} 
experiências, desenvolve a expressão e o diálogo, bem como o olhar investigativo, que assumem grande relevância em sua prática profissional futura (ALARCÃO, 2007).

\title{
2.3 A formação do professor reflexivo
}

As pesquisas de Schön (2000) discutem a relação entre teoria e prática na constituição dos profissionais da educação. Ele faz uma crítica à perspectiva de formação do professor que, muitas vezes, privilegia a racionalidade técnica, na qual o papel do pesquisador é considerado diferente e superior ao papel do profissional engajado na prática. Schön ressalta o papel da reflexão na ação prática do profissional:

\begin{abstract}
Muitas vezes, uma situação problemática apresenta-se como um caso único. Uma médica reconhece um conjunto de sintomas que não consegue associar a nenhuma doença conhecida. Um engenheiro mecânico encontra uma estrutura para a qual ele não pode, com as ferramentas à sua disposição, fazer uma determinada análise. Uma professora de aritmética, ao escutar a pergunta de uma criança conscientiza-se de um tipo de confusão e, ao mesmo tempo, de um tipo de compreensão intuitiva para a qual ela não tem qualquer resposta disponível. E porque o caso único transcende as categorias da teoria e da técnica existentes, o profissional não pode tratá-lo como um problema instrumental a ser resolvido pela aplicação de uma das regras de seu estoque de conhecimento profissional. O caso não está no manual. Se ele quiser tratá-lo de forma competente, deve fazê-lo através de um tipo de improvisação, inventando e testando estratégias situacionais que ele mesmo produz. (SCHÖN, 2000, p. 17).
\end{abstract}

É inegável que, apesar da atividade reflexiva ser inata ao ser humano, ela precisa de condições favoráveis para se manifestar; nesse sentido, pode-se dizer que ela se desenvolveria melhor em contextos de liberdade e responsabilidade. Para Alarcão (2007), em consonância com Schön (2000) é preciso vencer a inércia e avançar, no sentido de interpretar realmente o fenômeno educativo e não somente descrevê-lo.

Junto a esse pensamento corroboram também as discussões de Freire (1996) que considera que o pensar crítico, implica num movimento dinâmico, dialético, entre o fazer e o pensar, sobre o que se está fazendo; possibilitando aberturas para transformações. Freire (1996) destaca ainda a importância da formação permanente do professor, valorizando o momento da reflexão crítica sobre a prática, fazendo dela, seu objeto de análise.

No caso da Alfabetização de Jovens e Adultos é preciso considerar que a formação crítica e reflexiva do professor é extremamente necessária. Ela deve perpassar por uma consciência política e investigativa da situação do analfabetismo no Brasil, e da exclusão social que esse contexto promove. Para Gadotti (2006), o público da EJA é fruto da exclusão à cidadania por não ser alfabetizado, processo que deveria ser efetivado no período da infância.

É necessário também, que os futuros docentes se insiram na realidade da educação brasileira, sobretudo refletindo sobre a situação do analfabetismo no Brasil, embasados numa perspectiva crítica e transformadora. Para Soares e Pedroso (2016 p. 259) "a experiência vivenciada por educandos e educadores pode se constituir em um eixo propício para a leitura crítica do mundo e para a construção de uma visão reflexiva que vá além do instituído, possibilitando a emergência do novo". Nesse contexto de ação profunda, destacamos o pensamento de Freire ao apontar que, para reconhecer a realidade opressora e lutar pela libertação dessa realidade, é necessário ganhar consciência crítica da opressão, na práxis dessa busca (FREIRE, 2005).

Assim, Freire (2005) reverbera em sua teoria que é somente libertando-se da força da realidade, através da emersão dela e a volta sobre ela, numa ação dialética, que é possível realizar 
a verdadeira práxis - que não seja somente a prática pela prática. A formação de futuros educadores com consciência crítica do seu papel transformador, e com possibilidades de atuação cidadã no locus em que irão atuar, possibilita um percurso formativo mais sólido e consistente.

\section{METODOLOGIA}

O percurso metodológico do estudo se realizou por meio da revisão bibliográfica, tendo em vista seu caráter documental para levantamento de informações sobre a temática apresentada. Foram selecionados artigos, cujos autores estão sintonizados com as abordagens referentes à formação de professores, alfabetização e letramento e a educação de jovens e adultos.

Realizou-se também uma análise dos relatórios dos oito alunos/residentes de pedagogia das faculdades integradas de Cataguases que desenvolveram o Projeto Residência Pedagógica (FIC / UNIS) numa escola da rede pública que oferece a modalidade de Educação de Jovens e Adultos. Para a inserção dos acadêmicos no ambiente escolar, foram realizadas capacitações iniciais e durante todo o processo do desenvolvimento do projeto, buscando os eixos temáticos, como oratória, oficinas práticas de Ciências, primeiros socorros, oficinas temáticas de literatura, gestão da sala de aula, alfabetização, confecção de materiais pedagógicos, dentre outros temas sempre integrando as especificidades da Educação de Jovens e Adultos.

\section{RESULTADOS E DISCUSSÃO}

Para atender o público da EJA, os residentes foram capacitados sobre os apontamentos e reflexões das especificidades do processo de alfabetização, que se realiza junto a um público de várias gerações: jovens, adultos e idosos, como também sobre a realidade desses sujeitos na atualidade.

Na turma em questão, onde foi desenvolvido o Projeto Residência Pedagógica, os alunos presentes estavam em diferentes etapas da alfabetização, desde o pré-silábico ao silábico alfabético. A idade média da turma era acima de 40 anos, em várias profissões e inclusive aposentados. Deve-se esclarecer que era a única escola da cidade que oferecia essa modalidade de ensino noturno: EJA primeiro segmento. Dessa forma, alguns alunos não residiam no bairro da escola campo, talvez por isso não fossem tão frequentes.

Os alunos EJA demonstravam uma relação muito afetiva com o professor regente (preceptor) da escola campo, que os incentivava muito. É necessário destacar, que no início do trabalho, os alfabetizandos mostraram-se um pouco arredios, mas em pouco tempo os residentes ganharam a confiança desses, construindo também uma relação afetiva. Os residentes, ao observarem e acompanharem a turma, juntamente com o preceptor, diagnosticaram aqueles alunos com mais dificuldade, e davam um tratamento diferenciado e mais acolhedor a eles. Assim, realizavam intervenções mais direcionadas à demanda dos alunos.

$\mathrm{Na}$ Regência, os residentes desenvolveram alguns projetos, entre eles, "Eu, minha cidade, meu mundo", em que se buscou conhecer o universo dos educandos, suas histórias relacionadas também à história da cidade. Outro projeto realizado bem pertinente à realidade da cidade de Cataguases foi "O Alagamento", através do qual foram promovidas leituras dos fatos relativos às enchentes na cidade, que inclusive afeta a escola.

Na regência também realizaram entre outras atividades a "Dinâmica da Afetividade", por meio da qual se buscou resgatar a autoestima dos alfabetizandos da EJA, através do reconhecimento 
de si mesmo e dos colegas. Essa dinâmica contribuiu muito para aumentar o envolvimento entre os alunos da turma. Um fato interessante relatado pelos residentes é que com o desenvolvimento do projeto, os alfabetizandos da EJA começaram a gostar e se interessar muito pelas atividades ministradas por esses, e que perguntavam por que esses não vinham mais vezes à escola.

Desde o início do desenvolvimento e preparação de suas atividades para construírem o seu fazer docente, os encontros foram permeados de discussões sobre a metodologia de Paulo Freire, privilegiando o diálogo com os alfabetizandos da EJA, preceptor e professores envolvidos. Nas reuniões buscou-se o universo vocabular daquele grupo, para prepararem as temáticas das aulas a serem realizadas. A escolha de palavras compostas por sílabas simples, mas considerando também o seu significado para aquele grupo, oportunizou aos residentes o entendimento do que seja realmente a concepção sobre palavras geradoras idealizadas por Freire (2005).

Os residentes, na maioria das vezes, se propuseram a desenvolver as atividades embasadas na teoria Freireana, na proposta construtivista e sócio interacionista. Freire $(2005,1996)$; Grossi (2010); Ferreiro $(1983,1984)$ Vygotsky (1998), bem como nas discussões de Arroyo (2017).

Durante todo percurso do residente na sua construção formativa buscou-se articular estratégias para a promoção de ações integradas entre a pesquisa, a formação docente, e seu campo de atuação. Através de abordagens nas diversas áreas, Ihes foi permitido transformar os objetos de estudo em objetos de ensino e aprendizagem.

Estas atividades, articuladas às Diretrizes Curriculares para a Educação de Jovens e Adultos (2001), buscaram propiciar o desenvolvimento de um trabalho com maior nível de reflexão sobre o seu próprio fazer pedagógico, como o domínio do conhecimento, do conteúdo curricular, bem como também das ações pedagógicas, que permitirão certamente uma práxis transformadora.

Ao se abordar o tema formação de professores, é preciso que se considere o conceito de reflexão na ação, já abordado por muitos teóricos. Paulo Freire (1996), em Pedagogia da Autonomia, evidencia importância do educador crítico, principalmente no que se refere à sua prática. Alarcão (2007) considera condição primordial para o professor da sociedade da informação, uma prática reflexiva.

Na visão da autora, o ser humano deve ter consciência de sua capacidade criadora e não meramente reprodutora de ideias e práticas exteriores. Essa reflexão também foi observada nos residentes durante, mas principalmente do meio para o final, do desenvolvimento do projeto Residência Pedagógica, que se configura como uma oportunidade de ação-reflexão-ação, num movimento dialético para formação de um docente crítico, capaz de promover mudanças em seu âmbito de ação.

Com relação a outras vivências na escola campo os residentes relatam o envolvimento na elaboração de vários eventos, alguns inclusive com a participação de toda a comunidade escolar: Ação Social com o jogador de futebol Davi Luiz; Festa da Primavera; Dia de Ação de Graças; Festa da Família; Reunião do Colegiado; Avaliação Institucional; Festa Julina. Essas participações e vivências foram também importantes para a formação docente dos residentes.

Para formar um professor, é necessário oportunizar o desenvolvimento da criticidade, bem como a construção de sua autonomia na busca do conhecimento. Isso se traduz em ações e estratégias que favoreçam a conquista dessas competências, como inovações na gestão e na prática docente. 
O Programa Residência Pedagógica, se configura, numa possibilidade de diferentes interações entre professores da Educação Básica, com acadêmicos de Licenciaturas (residentes), que estão no início de sua formação, e em cujas ações, experiências são compartilhadas. À vista disso, na análise da prática docente, as pesquisas em educação realizadas por Libâneo, 2008; Cunha, 2006; Nóvoa, 2007; Weizs, 2006, Schön (2000) dentre outros, convergem para um processo educacional que alicerce a sociedade, valendo-se das melhores práticas pedagógicas, o que pode acontecer via essa rede de formação, como também observada no projeto residência pedagógica da FIC/UNIS.

Essa rede de formação contribui de maneira significativa para a robustez do estágio supervisionado, pois antes do Programa Residência Pedagógica, o processo de estágio era orientado apenas pelo docente da disciplina. Ao participarem do programa RP essa orientação é conduzida por uma rede de formadores (professores da IES e da escola Campo), essa rede se amplia e se consolida com a socialização dos resultados, em reuniões mensais e, principalmente através dos seminários no final de cada semestre, quando acontece a culminância do projeto. Nesse evento tem-se a presença de um público maior, para apresentação, discussão e avaliação das potencialidades e fragilidades, verificadas nas atividades desenvolvidas durante todo o tempo de realização das atividades.

Pelo que se observa na literatura, desenvolver o projeto residência pedagógica na Educação de jovens e adultos contribui para elucidar os desafios da formação de professores nesse segmento, historicamente muitas vezes negligenciado. Nesse estudo foi apontado pelos residentes a falta de material didático direcionado a esse público. Também afirmam Venturi e Bomfim (2015) que a EJA é "alvo de metas modestas, as políticas públicas são descontinuadas e fragmentadas, iniciativas focais e aligeiradas, a EJA traduz um projeto societário no qual a universalização da educação básica de qualidade para todos vem sendo assunto menor" (VENTURI E BOMFIM, 2015, p.214).

\section{CONSIDERAÇÕES FINAIS}

Os alunos da EJA, na escola pública, são estudantes do curso noturno e com histórias de exclusão ao ambiente escolar na infância, por necessidades de inserção no trabalho, desde muito cedo e dificuldades de acesso e permanência no ambiente escolar. A escolha da modalidade de Educação de Jovens e Adultos, para o Programa Residência Pedagógica, proporcionou aos residentes a possibilidade de observação na prática do processo de alfabetização de jovens e adultos, da forma como eles constroem o conhecimento, as hipóteses de escrita e leitura, bem como a possibilidade de desenvolvimento de metodologias e materiais adequados para o público da EJA.

Os alunos da EJA construíram relações afetivas com o preceptor (professora regente) e residentes, que favoreceram o desenvolvimento cognitivo da turma. Os residentes através do planejamento das atividades, como projetos temáticos e de sequências didáticas envolveram os educandos e permitiram seu engajamento com o conteúdo escolar. Deve-se destacar que às vivências junto à direção da escola, equipe de supervisão e funcionários permitiram ao acadêmico/residente um entendimento maior, sobre a dinâmica escolar e sua organização.

O Programa Residência Pedagógica, em seu bojo, propõe ações que visam aproximar o residente, acadêmico de Pedagogia em formação, à realidade da educação básica, incluindo a Educação de Jovens e Adultos. Por meio das atividades e vivências experimentadas na trajetória do programa, tiveram a oportunidade de refletir sobre práticas e ações pedagógicas, atuando de acordo com a proposta reflexiva (ação -reflexão -ação), que certamente contribuíram em seu 
percurso formativo. Dessa forma, constata-se a relevância da teoria Freireana e do Programa Residência Pedagógica na formação do futuro professor para atuar na Educação de Jovens e Adultos.

Deve-se destacar que o Programa Residência Pedagógica contribui na melhoria da educação básica, uma vez que o mesmo pode promover a reestruturação dos estágios obrigatórios que balizam a formação de professores nas IES. O programa vem de forma ímpar articular estratégias, para a promoção de ações na formação do residente.

No processo de formação do professor, o estágio supervisionado é um componente curricular integrante do Projeto Político Pedagógico dos cursos de licenciatura, visto que é um eixo articulador entre a formação docente e o mundo do trabalho. No programa RP, o estágio é acompanhado por uma rede de formadores (professores da escola campo de da IES) proporcionando ao residente o domínio de instrumentos teóricos e práticos, imprescindíveis à execução de suas funções, preparando- o de forma mais fundamentada e efetiva para uma prática transformadora.

\section{REFERÊNCIAS}

ALARCÃO, Isabel. Professores Reflexivos em uma escola reflexiva. São Paulo: Cortez, 2007.

ARROYO, Miguel González. Formar educadoras e educadores de jovens e adultos. In: Seminário Nacional sobre Formação Do Educação de Jovens e Adultos. Belo Horizonte: Autêntica, 2006.

ARROYO, Miguel Gonzáles. Passageiros da noite: do trabalho para a EJA. Itinerários pelo direito a uma vida justa. Petrópolis: Vozes, 2017.

BECKER, Fernando. Da Ação à Operação: O Caminho da Aprendizagem em Jean Piaget e Paulo Freire. Porto Alegre: Palmarinca; 1993.

BRASIL. Lei de Diretrizes e Bases da Educação Nacional. Lei n. 9.394, de 20 de dezembro de 1996. Estabelece as diretrizes e bases da educação nacional. Diário Oficial da União, Brasília, DF, 23 dez. 1996. Disponível em: <http://www.planalto.gov.br/ccivil_03/leis/19394.htm> Acesso em: 19 de jun 2020.

BRASIL. CNE/CEB. Parecer no 11/2000. Diretrizes Curriculares Nacionais para a Educação de Jovens e Adultos. Relator: Carlos Roberto Jamil Cury, aprovado em 10/05/2000. Diário Oficial da União, MEC/CNE/CEB, Brasília, 9 jun. 2000, Seção 1e, p. 15 Disponível em <http://portal.mec.gov.br/secad/arquivos/pdf/eja/legislacao/parecer_11_2000.pdf> Acesso em: em 13 jun 2020.

BRASIL. Ministério da Educação, Secretaria de Educação Fundamental. Proposta curricular para a educação de jovens e adultos: primeiro segmento do Ensino Fundamental. Brasília: MEC/SEF, 2001. Disponível em: <http://portal.mec.gov.br/secad/arquivos/pdf/eja/ propostacurricular/primeirosegmento/propostacurricular.pdf> Acesso em: 19 junho 2020. 
CUNHA, Maria Isabel. Docência na universidade, cultura e avaliação institucional: saberes silenciados em questão. Revista Brasileira de Educação - ANPED. Rio de Janeiro: v. 11, n. 32, p. 258-271, 2006.

FERREIRA, Edna Maria de Oliveira; VITORINO, César Costa. Passageiros da noite: do trabalho para a EJA. Itinerários pelo direito a uma vida justa. Revista Brasileira de. Educação, v. 24, e240007, 2019.

FERREIRO, Emília et al. Los adultos no-alfabetizados y sus conceptualizaciones del sistema de escritura. Cadernos Investigaciones Educativas, México, n.10, 1983.

FERREIRO, Emília; TEBEROSKY, Ana. A psicogênese da língua escrita. Porto Alegre: Artes Médicas, 1984.

FRIEDRICH, Márcia et al. Trajetória da escolarização de jovens e adultos no Brasil: de plataformas de governo a propostas pedagógicas esvaziadas. Ensaio: avaliação de políticas públicas em educação, v. 18, n. 67, p. 389-410, 2010.

FREIRE, Paulo. Pedagogia da Autonomia. São Paulo: Editora Paz e Terra; 1996.

FREIRE, Paulo. Pedagogia do oprimido. 46. ed. Rio de Janeiro: Paz e Terra, 2005.

FREIRE, Paulo. A importância do ato de ler. 51. ed. São Paulo: Editora Cortez, 2011. Col. Polêmicas da nossa época.

GADOTTI, Moacir; ROMÃO, José Eustáquio. Educação de jovens e adultos: teoria prática e proposta. 8. ed. São Paulo: Cortez, 2006.

GROSSI Esther Pillar. Didática dos níveis pré-silábicos. 10 ed. Rio de Janeiro. Paz e Terra; 2010.

HADDAD, Sérgio; DI PIERRO, Maria Clara. Escolarização de jovens e adultos. Revista Brasileira de Educação, São Paulo, n. 14, p. 108-130, 2000.

IBGE. Instituto Brasileiro de Geografia e Estatística: dados sobre educação. Disponível em: <https://educa.ibge.gov.br/jovens/conheca-o-brasil/populacao/18317educacao.html\#: :text=No\%20Brasil\%2C\%20segundo\%20a\%20Pesquisa,havia\%20sido\%206\%2C8 \%25>. Acesso em: 01 out 2020.

LIBÂNEO, José Carlos. Reflexividade e formação de professores: outra oscilação do pensamento pedagógico brasileiro? In: PIMENTA, S. G.; GHEDIN, E. (Orgs.) Professor reflexivo no Brasil: gênese e crítica de um conceito. São Paulo: Cortez, 2008, p. 53-79.

MACHADO, Maria Margarida. A prática e a formação de professores na EJA: uma análise de dissertações e teses produzidas no período de 1986 a 1998. In: Reunião anual da ANPED, 23, 2000, Associação Nacional de Pós-graduação e Pesquisa em Educação, Caxambu, 2000. (Edição 
eletrônica). Disponível em: <http://23reuniao.anped.org.br/textos/1822t.PDF> Acesso em: 29 mai 2020.

NÓVOA, Antônio. Evidentemente. In: FARO, J. S.; GUTIERRE, P. (Eds.) Desafios do trabalho do professor no mundo contemporâneo, São Paulo: SIMPRO, 2007. Disponível em:

https://www.sinprosp.org.br/arquivos/novoa/livreto_novoa.pdf. Acesso em: 12 abr 2020.

NÓVOA, Antônio. Entrevista: A escola o que é da escola. Revista Escola Gestão Educacional. São Paulo: n. 8, p. 23-25, jun./jul. 2010.

OLIVEIRA, Marta Kohl. Analfabetos na sociedade letrada: diferenças culturais e modos de pensamento. Travessia, v. 5, n. 12, p. 17-20, 2007.

OLIVEIRA, Marta Kohl. Organização conceitual e escolarização. In: OLIVEIRA, Marcos Barbosa de; OLIVEIRA, Marta Kohl (Orgs.). Investigações cognitivas: conceitos, linguagem e cultura. Porto Alegre: Artes Médicas Sul, 1999. p. 81- 99.

PAIVA, Vanilda. Educação popular e educação de adultos. São Paulo: Loyola, 1973. v. 1. (Temas Brasileiros, 2).

PAIVA, Jane. Tramando concepções e sentidos para redizer o direito à educação de jovens e adultos. Revista Brasileira de Educação. São Paulo, n. 33, p. 519-566, 2006.

PAIVA, Jane; HADDAD, Sérgio; SOARES, Leôncio José Gomes. Pesquisa em educação de jovens e adultos: memórias e ações na constituição do direito à educação para todos. Revista Brasileira de Educação, v. 24, e240050, 2019.

PIAGET, Jean. Para onde vai a educação? Rio de Janeiro: José Olympio Editora, 1984.

SCHÖN, Donald. Educando o profissional reflexivo: um novo design para o ensino e a aprendizagem. Trad.Roberto Cataldo Costa. Porto Alegre: Artmed, 2000.

SOARES, Leôncio José Gomes. O educador de jovens e adultos e sua formação. Educação em Revista, Belo Horizonte, n. 47, p. 83-100, 2008.

SOARES, Leôncio José Gomes; PEDROSO, Ana Paula Ferreira. Formação de educadores na educação de jovens e adultos (eja): alinhavando contextos e tecendo possibilidades. Educação em Revista, Belo Horizonte, v. 32, n. 4, p. 251-268, 2016.

SOARES, Magda. Letramento e escolarização. In: RIBEIRO, Vera M. (org.) Letramento no Brasil. São Paulo: Global, 2003.

UNESCO. Declaração de Hamburgo sobre a educação de adultos e plano de ação para o futuro. In: Conferência Internacional sobre a Educação de Adultos, 1997, Hamburgo. Anais... Hamburgo, Alemanha, 1997. 
VYGOTSKY, Lev Semenovitch. Formação Social da Mente. São Paulo: Martins Fontes, 1998.

WEISZ, Telma. O diálogo entre o ensino e a aprendizagem. 2. ed. São Paulo: Ática, 2006. 135p. 